\title{
Motor and Behavioral Changes in Mice With Cisplatin-Induced Acute Renal Failure
}

\author{
B. H. ALI ${ }^{1}$, A. RAMKUMAR ${ }^{1}$, T. T. MADANAGOPAL ${ }^{1}$, M. I. WALY ${ }^{2}$, M. TAGELDIN ${ }^{3}$, \\ S. AL-ABRI ${ }^{4}$, M. FAHIM ${ }^{5}$, J. YASIN $^{6}$, A. NEMMAR $^{5}$
}

${ }^{1}$ Department of Pharmacology and Clinical Pharmacy, College of Medicine and Health Sciences, ${ }^{2}$ Departments of Food Science and Nutrition, and ${ }^{3}$ Department of Animal and Veterinary Science, College of Agricultural and Marine Sciences, ${ }^{4}$ College of Medicine and Health Sciences, Sultan Qaboos University, Muscat, Sultanate of Oman, ${ }^{5}$ Department of Physiology, and ${ }^{6}$ Department of Internal Medicine, College of Medicine and Health Sciences, United Arab Emirates University, Al Ain, United Arab Emirates

Received June 5, 2013

Accepted August 1, 2013

On-line November 1, 2013

\section{Summary}

We have previously shown that chronic renal failure in rats induces changes in motor activity and behavior. Similar work on the possible effects of acute renal failure (ARF) induced by cisplatin (CP) is lacking. This is the subject matter of the current work. $\mathrm{CP}$ was injected intraperitoneally (i.p.) at a single dose of $20 \mathrm{mg} / \mathrm{kg}$ to induce a state of $A R F$, and three days later, its effects on motor activity, thermal and chemical nociceptive tests, neuromuscular coordination, pentobarbitone-sleeping time, exploration activity and two depression models were investigated. The platinum concentration in the kidneys and brains of mice was also measured. The occurrence of CP-induced ARF was ascertained by standard physiological, biochemical and histo-pathological methods. CP induced all the classical biochemical, physiological and histopathological signs of ARF. The average renal platinum concentration of $\mathrm{CP}$-treated mice was $5.16 \mathrm{ppm}$, but there was no measurable concentration of platinum in the whole brains. CP treatment significantly decreased motor and exploration activities, and increased immobility time in depression models, suggesting a possible depression-like state. There was also a significant decrease in neuromuscular coordination in $\mathrm{CP}$-treated mice. $\mathrm{CP}$, given at a nephrotoxic dose, induced several adverse motor and behavioral alterations in mice. Further behavioral tests and molecular and biochemical investigations in the brains of mice with $\mathrm{CP}$-induced ARF are warranted.

\section{Key words}

Cisplatin $\bullet$ Acute renal failure $\bullet$ Mice $\bullet$ Behavior $\bullet$ Motor activity

\section{Corresponding author}

Badreldin H. Ali, Department of Pharmacology and Clinical Pharmacy, College of Medicine and Health Sciences, Sultan Qaboos University, Al Khod, P.O.Box 35, P.C 123, Muscat, Sultanate of Oman. E-mail: alibadreldin@hotmail.com, akthmali@squ.edu.om

\section{Introduction}

Cisplatin [cis-DDP cis Diammine Dichloro Platinum (II)] (CP) is a commonly used chemotherapeutic agent in the treatment of solid tumors in various organs (Sanchez-Gonzalez et al. 2011). However, its dosedependent nephrotoxicity is considered to be one of its major limitations (dos Santos et al. 2012, Leu and Baribeault 2010). The drug causes apoptosis (Kong et al. 2013) and DNA damage ( $\mathrm{Li}$ and Schluesener 2006) and induces oxidative stress and inflammation (Chirino and Pedraza-Chaverri 2009, Kang et al. 2009), affecting the proximal straight and distal convoluted tubules of kidney, resulting in acute renal injury (Ali and Al Moundhri 2006, Mitazaki et al. 2013). At the molecular level, it has been found that the S3 segment of the proximal tubules is damaged due to the high expressions of copper transporter receptor1 (Ctr 1) and inorganic cation 
receptor2 (Oct 2), which transport $\mathrm{CP}$ to the kidney tubules making the renal tissues high in platinum compared with other organs (Pabla et al. 2009, Pabla and Dong 2012). Studies also proved that CP causes neurotoxicity and hepatotoxicity by damaging the mitochondria causing increases in mitochondrial lipid peroxidation and protein carbonyl contents in brain tissues (Waseem and Parvez 2013).

Acute renal failure (ARF) is defined as a state of rapid loss of kidney function which increases concentrations of serum creatinine and urea resulting in the inability of the kidney to regulate acid-electrolyte balance, and failure to excrete fluids and waste products (Akcay et al. 2010). Acute kidney injury (also called ARF) is a serious condition that is commonly encountered in many categories of patients, including those that are critically ill (Andreoli 2009).

Several studies have reported on the changes in the central nervous system (CNS) that are ascribed to uremic toxins and inflammation caused by the alterations in the hormonal activities within brain in patients with chronic kidney disease (CKD) (Zalai et al. 2012, Hedayati et al. 2012). We have previously shown that rats with experimental CKD exhibit impaired motor activity and behavior (Ali et al. 2011). However, similar studies on the effect of either clinical or experimental ARF are, as far as we are aware, lacking.

As far as we are aware, there are no reports on the effect of $\mathrm{CP}$-induced $\mathrm{ARF}$ on the central nervous system (CNS) in experimental animals resulting in motor or behavioral changes, although there are few studies reporting some cognitive complaints in cancer patients on CP (Pedersen et al. 2009). Therefore, the aim of our current study was to investigate the possible effects of CP-induced ARF on the motor activity and some selected behavioral parameters in mice.

\section{Methods}

Animals

Male Albino mice $(n=212)$ weighing between 32-38 g were obtained from the Small Animal House of Sultan Qaboos University (SQU). They were housed, three to a cage to reduce stress, in polypropylene cages, and given standard nutritionally adequate-laboratory chow diet (Oman Flour mills, Muscat, Oman) and normal tap water ad libitum, at ambient temperature of $22 \pm 2{ }^{\circ} \mathrm{C}$, humidity $(60 \%)$ and $12 \mathrm{~h}$ light:dark cycle (light on at 6.00 AM). The mice were acclimated to their housing for seven days before the start of the study, which was approved by SQU Animal Ethical Committee, and conducted according to International laws and policies (EEC Council directives 86/609, OJL 358, 1 December 1987; NIH Guide for care and Use of Laboratory Animals, NIH Publication No. 85-23, 1985).

\section{Treatments}

The animals were randomly selected and divided into control (given $0.9 \% \mathrm{NaCl}$ ), and $\mathrm{CP}$ treated (injected with the drug intraperitoneally (i.p.) at a single dose of $20 \mathrm{mg} / \mathrm{kg}$, and sacrificed three days later. Initial and final body weights of the animals were recorded before the treatments and just before sacrifice. Mice were placed in metabolic cages $24 \mathrm{~h}$ prior to sacrifice in order to collect urine, and were then anaesthetized by ketamine $(7.5 \mathrm{mg} / \mathrm{kg}$ i.p.) and xylazine $(10 \mathrm{mg} / \mathrm{kg}$ i.p.) for collection of blood, kidneys and whole brain. The blood (about $1.5 \mathrm{ml}$ ) was collected from the abdominal aorta in heparinized tubes and was centrifuged at $900 \mathrm{~g}$ for $15 \mathrm{~min}$ at $4{ }^{\circ} \mathrm{C}$ to obtain plasma. The plasma obtained was stored at $-80^{\circ} \mathrm{C}$ for a week or less pending analyses. The kidneys and whole brain were quickly removed and either frozen immediately in liquid nitrogen or fixed with $10 \%$ buffered formalin. At the end, animals were killed by overdose of anesthesia.

\section{Biochemical analyses}

The concentrations of plasma creatinine and urea, and creatinine clearance, as well as NAG activity in urine were measured spectrophotometrically, as described before (Ali et al. 2010). Platinum concentration was measured in the kidneys and whole brain from both controls and CP-treated mice as detailed elsewhere (AlKharusi et al. 2013). Briefly, the tissues were dissolved in 15.7 $\mathrm{M}$ nitric acid and 11.5 $\mathrm{M}$ hydrochloric acid. The samples were then kept in a water bath at $100^{\circ} \mathrm{C}$ for $2 \mathrm{~h}$. The platinum concentration was finally measured using an inductively coupled plasma (ICP) machine.

\section{Motor and behavioral experiments}

The animals were subjected to the following tests on the fourth day after injection of either $\mathrm{CP}$ or saline prior to their sacrifice. In all experiments, and within each behavioral test, each mouse was used once.

\section{Thermal and chemical nociceptive tests}

a) Hot plate test: The animals $(\mathrm{n}=24)$ were gently placed into a glass cylinder on a hot plate 
analgesia meter (Ugo Basile, Comerio VA, Italy), maintained at a temperature of $55 \pm 0.2^{\circ} \mathrm{C}$. The time taken by the animal to either lick its paw or jump off the plate is considered as its response (Eddy and Leimbach 1953). In order to prevent tissue damage in mice, the cut off time was fixed at $15 \mathrm{~s}$.

b) Warm-water tail flick test: The tail of every mouse $(n=24)$ was immersed $2-3 \mathrm{~cm}$ in a beaker containing warm water maintained at a temperature of $54-55^{\circ} \mathrm{C}$. The time between the moment the tail was immersed and its removal from the water was calculated using a stop watch (Wild et al. 1993) and $15 \mathrm{~s}$ was considered as minimum cut off time.

c) Abdominal constriction (Writhing test): Both groups of mice $(\mathrm{n}=12$, each) were injected with acetic acid $(0.6 \% \mathrm{v} / \mathrm{v})$ in a volume of $20 \mathrm{ml} / \mathrm{kg}$ i.p. (Collier et al. 1968). Contraction of abdominal muscle and stretching of hind limbs caused by abdominal constrictions induced were observed for $15 \mathrm{~min}$ after the administration of the acid, and the number of contractions was counted.

\section{Motor activity}

Motor activity of the animals was measured using a digitalized activity meter (Ugo Basile, Comerio VA, Italy). The vertical and horizontal movements of the animals $(n=20)$ within a period of $15 \mathrm{~min}$ were recorded, but the values were excluded for the first $5 \mathrm{~min}$ from zero time after the animals had been placed within the activity cage (Ali et al. 1999, Ali et al. 2011).

\section{Neuromuscular coordination tests}

a) Rota rod treadmill test: Animals $(\mathrm{n}=20)$ were gently placed on the Rota rod treadmill (Ugo Basile, Comerio VA, Italy) to study the muscular activity in control and treated mice. The apparatus used was subdivided into 5 segments by discs with a diameter of $24 \mathrm{~cm}$, and the rod was $30 \mathrm{~cm}$ long and $3 \mathrm{~cm}$ in diameter. The rod was rotated at a fixed speed of 25 revolutions / min and the time taken by the animal to fall from the rotating rod was automatically recorded.

b) Grip strength test: A simple manual apparatus was devised with two wooden poles of $30 \mathrm{~cm}$ length, connected with a smooth wire of $15 \mathrm{~cm}$ length, where the animals $(n=20)$ were made to hang using their fore limbs. The time taken by the animal to drop from the wire was recorded using a stop watch. In some experiments a grip strength apparatus (Ugo Basile, Comerio VA, Italy) was also used.

\section{Sleeping time test}

Sodium pentobarbitone at an i.p. dose of $30 \mathrm{mg} / \mathrm{kg}$ was injected into mice $(\mathrm{n}=16)$, and the time taken to induce sleep, and the duration of sleep for each animal was recorded. Sleeping time was taken as the interval between the loss and regaining of the righting reflex (Fujimori 1965).

\section{Exploration activity test}

An automated hole board apparatus (Ugo Basile, Comerio VA, Italy) was used to carry out this test based on the design and principle that has been reported earlier (File 1973). The animals $(n=16)$ were gently placed on the centre of the board and the time taken by each animal for the first dip, the number of holes dipped and the total number of dips was digitally recorded for $10 \mathrm{~min}$.

\section{Depression-like behavior}

Forced swimming test (FST): The animals $(\mathrm{n}=16)$ were forced to swim in a cylinder of height $25 \mathrm{~cm}$ and diameter $19 \mathrm{~cm}$, containing water up to an height of $17 \mathrm{~cm}$, maintained at a temperature of $25 \pm 1^{\circ} \mathrm{C}$, for a total duration of $6 \mathrm{~min}$, out of which the first two minutes were considered as a trial and the total immobility time was calculated during the final 4 min of swimming (Castagne et al. 2011). Immobility time was considered when the animal stops struggling and remains motionless in the water.

Tail suspension test (TST): A computerized apparatus (purchased from Med associates, Inc, St. Albans, Vermont, USA) was used to perform the technique of TST based on the report of (Steru et al. 1985). The animals $(n=16)$ were suspended using an adhesive tape on the tip of the rod. This rod, attached to the chamber, has a sensor which detects the mobility of the animal for a period of $6 \mathrm{~min}$. The immobility time was calculated during the last $4 \mathrm{~min}$ of the experiment, excluding the initial two minutes trial.

\section{Effect of naloxone on CP-induced anti-nociception}

Animals $(n=16)$ were given the opioid receptor antagonist naloxone, at an i.p. dose of $1.5 \mathrm{mg} / \mathrm{kg}, 15 \mathrm{~min}$ before subjecting them to the anti-nociceptive tests as described before (Ali et al. 1995). To study the effect of naloxone, the same animals were first placed on the hot plate before giving the injection, and the time taken by them to stay on the hotplate was calculated. Later, the difference between the results recorded before and after giving naloxone was compared. 
Table 1. Body weight changes and relative kidney and brain weights in control and CP-treated mice.

\begin{tabular}{lccc}
\hline $\begin{array}{l}\text { Group / } \\
\text { Parameter }\end{array}$ & $\begin{array}{c}\text { Body weight } \\
\text { change \% }\end{array}$ & $\begin{array}{c}\text { Relative } \\
\text { kidney } \\
\text { weight \% }\end{array}$ & $\begin{array}{c}\text { Relative } \\
\text { brain } \\
\text { weight \% }\end{array}$ \\
\hline $\begin{array}{l}\text { Control } \\
\text { CP-treated }\end{array}$ & $-6.39 \pm 0.91 \pm 0.77^{* * *}$ & $1.63 \pm 0.04$ & $1.69 \pm 0.06$ \\
$1.96 .13^{*}$ & $1.38 \pm 0.02^{* *}$ \\
\hline
\end{tabular}

Values in the table are mean \pm SEM $(n=10-12)$. Body weight values were expressed as $\%$ of difference between the final and initial weights before the start of the treatment in each group. Relative kidney and brain weights were the percentage of the weights of the organs divided by the final body weight of the mice. Animals were injected with saline $(0.9 \% \mathrm{NaCl})$ or cisplatin $(\mathrm{CP})$, at a dose $20 \mathrm{mg} / \mathrm{kg}$ and sacrificed after three days. ${ }^{*} P<0.05$, compared to Control group. ${ }^{* *} P<0.01$, compared to Control group. ${ }^{* * *} P<0.001$, compared to Control group

\section{Histopathological assessment}

Both kidneys were removed and their weights recorded. A small piece of the left kidney was fixed in $10 \%$ formalin. The tissue was dehydrated with increasing concentrations of ethanol, cleared with xylene, and embedded in paraffin. Structural studies were made on paraffin embedded kidney sections $(3 \mu \mathrm{m})$ stained with hematoxylin and eosin (H\&E), using a light microscope. Histopathological evaluation was carried out by an observer unaware of the treatments, and assigned a score, which represents the approximate extent of necrotic area in the cortical tubules on a scale of 0-4 ( 0 - no necrosis; 1 - a few local necrotic spots; 2 - necrotic area was about one half; 3 - tubular necrosis $>60 \% ; 4$ - nearly the entire area was necrotic).

\section{Drugs and chemicals}

Cisplatin used was obtained from $\mathrm{PCH}$ Pharmacheme (Haarlem, Netherlands); sodium pentobarbital from Sigma (St. Louis, MO, USA); naloxone from Mylan S.A.S (St. Priest, France); acetic acid from British Drug House (Dorset, U.K); creatinine and urea kits from Human $\mathrm{GmbH}$ (Mannheim, Germany); $\mathrm{N}$-acetyl- $\beta$-D-glucosaminidase (NAG) assay kit from Diazyme Laboratories (Poway, CA, USA).

The rest of the chemicals were Analytical Reagent grade.

\section{Statistical analysis}

Statistical analyses and comparisons were carried out by the $t$ test, using a commercial statistical software package (Graph Pad, San Diego, CA, U.S.A).
Data are given as mean \pm SEM. A $P$ value less than 0.05 were considered significant.

\section{Results}

\section{Body, kidney and brain weights}

These results are summarized in Table 1. After the administration of $\mathrm{CP}$, the body weights of the animals decreased significantly $(P<0.0001)$ by about $-6.8 \%$, when compared with the controls, whose body weights had increased by about $4.4 \%$. The relative kidney weight (as a per cent of final body weight) of CP-treated mice showed significant increase $(P<0.05)$, whereas that of the whole brain showed significant decrease when compared with that of the controls (Table 1).

\section{Biochemical and histological indices of ARF}

The plasma creatinine and urea concentrations were significantly higher in CP-treated animals than in controls (Fig. 1A, 1B), and creatinine clearance was insignificantly lower in the treated group than in the controls (Fig. 1C). The urinary activity of NAG was also significantly elevated in the treated group (Fig. 1D). The average $( \pm$ SEM) platinum concentration in the kidneys of CP-treated mice was $5.16 \pm 0.724 \mathrm{ppm}(\mathrm{n}=8)$, and no measurable concentration was found in the kidneys of control mice. Also, no measurable concentration of platinum was found in the whole brains of control and CP-treated mice. ARF was also confirmed histologically. In the $\mathrm{CP}$-treated group, the mean percentage of tubular necrosis was about $85.8 \%$ (given a score of 4 ), whereas in the saline-treated (control) group, there was no tubular necrosis, and was given a score of zero (Fig. 2).

\section{Motor and behavioral studies}

\section{Thermal and chemical nociceptive tests}

The time taken by CP-treated mice on the hot plate was significantly longer than that of the control group (Fig. 3A). In the tail flick test, the time required to withdraw the tail was significantly longer in the $\mathrm{CP}$ treated mice than in the controls (Fig. 3B). The CPtreated animals had fewer abdominal constrictions in response to the acetic acid injection than the control (Fig. 3C).

Motor activity and neuromuscular coordination tests

The locomotor activity in CP treated animals 
A

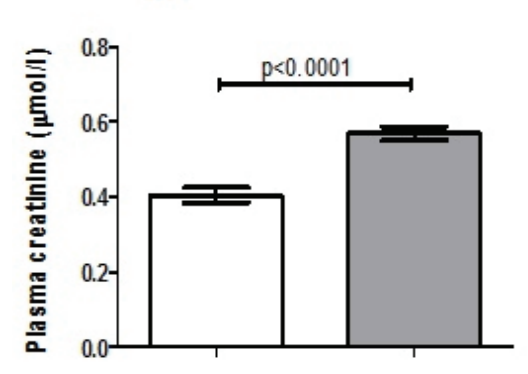

C

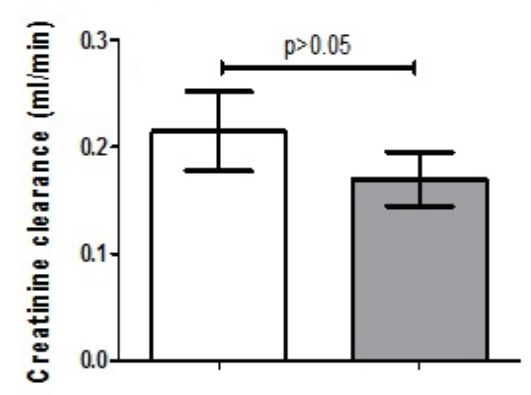

A

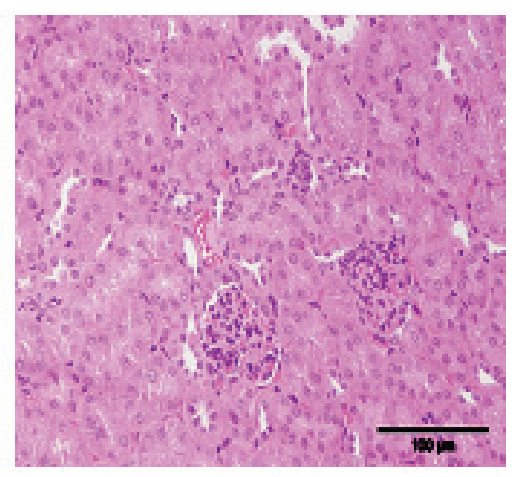

Fig. 1. Some renal function tests in control mice and mice treated with cisplatin. A) Plasma creatinine concentration, B) Plasma urea concentration, C) Creatinine clearance, D) Activity of NAG in urine. Each column and vertical bar represent mean \pm SEM $\quad(n=6-8)$. Differences between the groups were assessed by t-test and $P<0.05$ was considered significant.
Fig. 2. Representative section of kidney histology using H\&E staining, in control and cisplatin (CP)-treated mice. A) Control mice with normal kidney architecture, and B) CPtreated mice with acute tubular necrosis greater than $60 \%$ of the examined area showing cast formation (single arrow), vacuolization (double arrow), loss of epithelial cells (arrow head) and necrosis $(*)$ was significantly lower $(P<0.01)$ than that of controls (Fig. 4A, 4B). Compared with the controls, CP treatment in mice significantly reduced the neuromuscular coordination (Fig. 4C) and grip strength (Fig. 4C).

\section{Exploration ability test}

There was a significant difference between the number of dips in the control and CP-treated mice (Fig. 5A). However, there were no significant differences for the time taken for the first dip and the number of holes dipped by mice in the two groups (Fig. 5B, 5C).

\section{Depression models}

In both depression models of FST and TST
(Fig. 5D, 5E), there was significant increase in the immobility time in CP-treated animals when compared with that of the controls.

\section{Effect of naloxone on anti-nociception}

There was no significant difference between the control and CP-treated groups with respect to the effect of naloxone on the anti-nociceptive action of $\mathrm{CP}$.

\section{Sleeping time test}

There was no significant difference between the control and CP-treated mice with respect to pentobarbitone-induced sleeping time, or time of onset of sleep. 
A

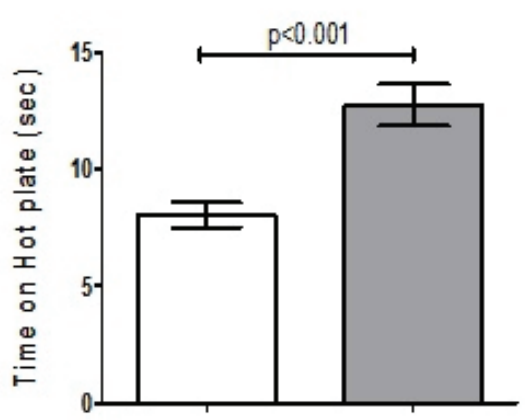

$\mathrm{B}$

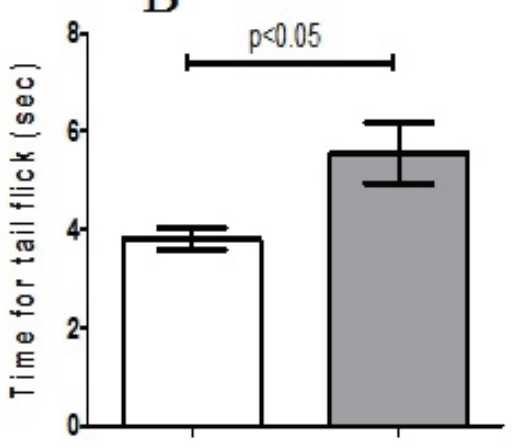

$\square$ Control

$\square$ CP-treated

$\mathrm{C}$

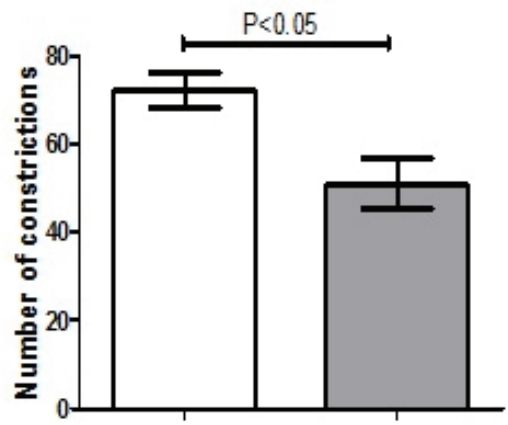

Fig. 3. Effect of thermal and chemical nociceptive tests in control mice and mice treated with cisplatin. A) Time taken on hot plate, B) Time taken for tail flick test, C) Number of abdominal constrictions during writhing test. Each column and vertical bar represent mean \pm SEM $(n=12-14)$. Differences between the groups were assessed by $t$-test and $P<0.05$ was considered significant.

A

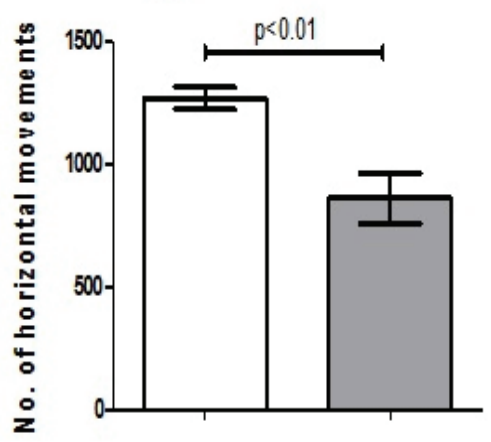

C

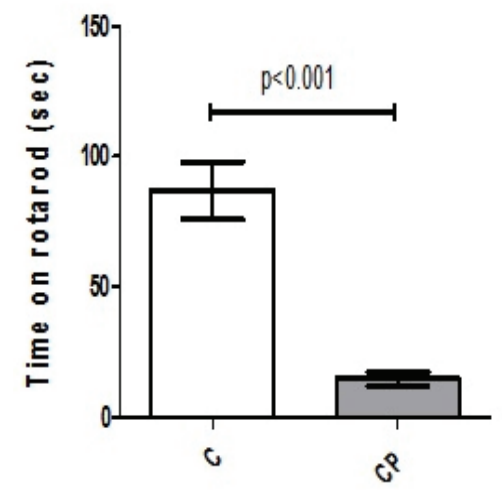

$\square$ Control

$\square$ CP-treated

B

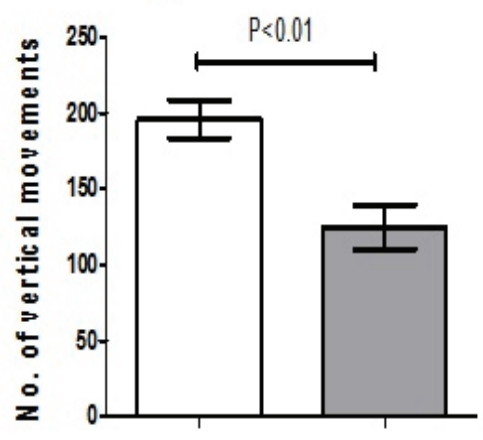

D

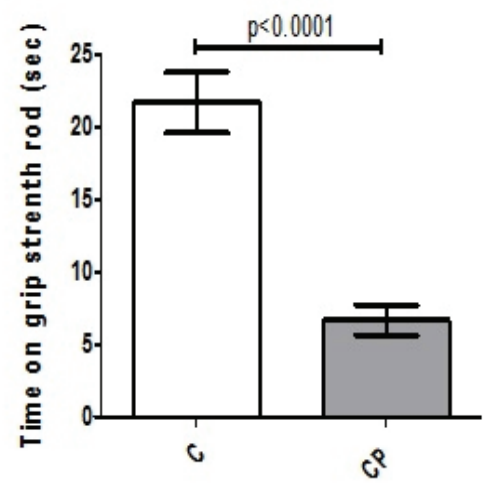

Fig. 4. Locomotion and neuromuscular coordination in control mice and mice treated with cisplatin. A) Number of horizontal movements, B) Number of vertical movements, C) Time taken on rotarod treadmill, and D) Time taken on grip strength rod. Each column and vertical bar represent mean \pm SEM $(n=10-12)$. Differences between the groups were assessed by t-test and $P<0.05$ was considered significant.

\section{Discussion}

ARF (or acute kidney injury) is increasingly prevalent in both developing and developed countries resulting in severe morbidity and mortality ( $\mathrm{Li}$ et al.
2013), and about $20 \%$ of ARF cases among hospitalized patients are due to $\mathrm{CP}$ nephrotoxicity and more than a third of the patients develop renal injury within 10 days after a single dose of CP (de Jonge and Verweij 2006). Therefore we studied the possible effects of $\mathrm{CP}$-induced 
A

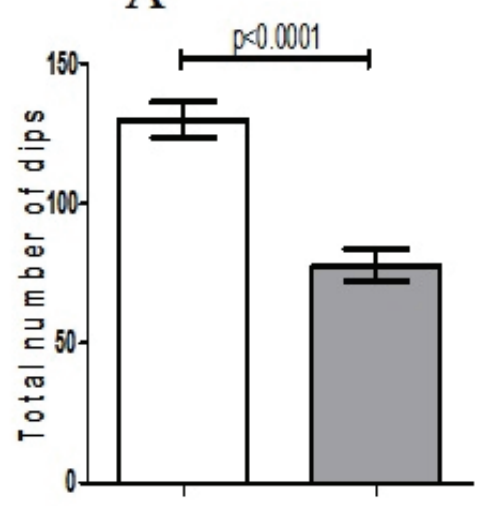

D

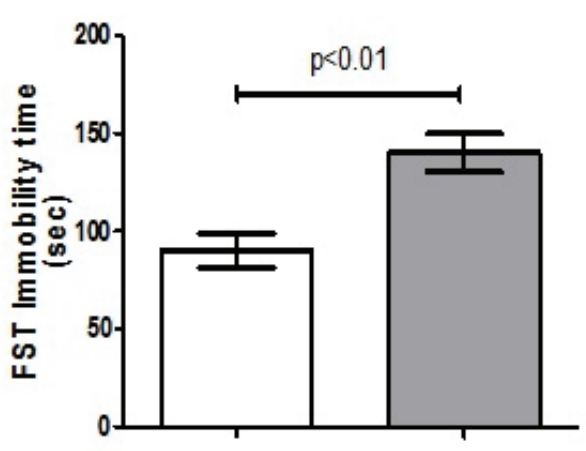

B

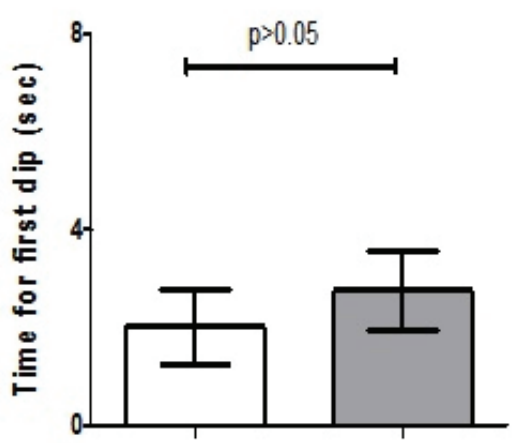

C

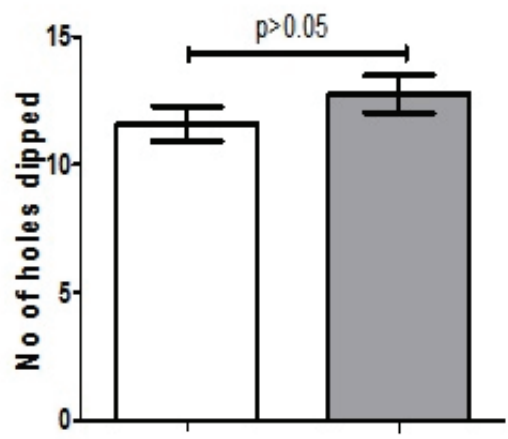

E

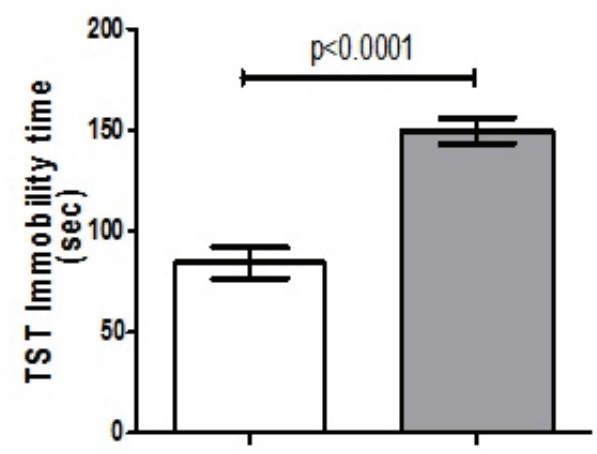

Fig. 5. Exploration activity and depression-like behavioral tests in control mice and mice treated with cisplatin. A) Time taken for first dip, B) Total number of dips in $10 \mathrm{~min}$, C) Number of holes dipped, D) Immobility time during forced swimming test (FST), and E) Immobility time during tail suspension test (TST). Each column and vertical bar represent mean \pm SEM ( $n=6-8$ ). Differences between the groups were assessed by t-test and $P<0.05$ was considered significant.

ARF on behavioral and motor activities in mice. As far as we are aware, such an attempt has not been made before. However, in a previous study, we have reported that experimental $\mathrm{CKD}$ due to adenine feeding resulted in significant motor and behavioral alterations in rats (Ali et al. 2011). An established set of behavioral tests were conducted here in order to quantify the motor and behavioral changes induced by ARF. Different aspects of validity of these tests have been well studied and their relevance to clinical situations confirmed (Castagne et al. 2011, Vervliet and Raes 2013).

It is known that housing conditions have significant physiological and psychological effects in mice (Balcombe 2006). In this study, particular care was paid to the housing conditions of both control and CPtreated mice, in order to avoid or minimize any possible adverse effects of the housing on their behavior (Balcombe 2006).

Significant loss of body weight was observed in mice treated with CP. This could be due to the alteration in their eating behavior, as a results of the cytotoxic effect of CP (Vera et al. 2006), or to renal tubular injury affecting re-absorption of water leading to dehydration (Ali et al. 2008) and /or inflammation (Pabla and Dong 2012). Kidney damage was also marked by elevated relative kidney weight due to the increase in glomerular volume and other cellular changes (Saad et al. 2000).

In this study, renal histopathology and biochemical markers such as plasma creatinine and urea and NAG activity in urine were measured so as to assess the magnitude of kidney injury and confirm the state of ARF. The platinum concentrations in kidney samples of CP-treated mice were significantly higher than in controls; however, no measurable platinum concentration was detected in the brain. This probably suggests that the metal does not cross the blood brain barrier, as was reported earlier (Bernocchi et al. 2011).

In the current study, we showed that mice with 
CP-induced ARF are susceptible to motor and behavioral changes, although the exact mechanisms involved are not certain. CP impaired locomotion, neuromuscular coordination, and grip strength in treated mice compared to the controls. The decrease in the motor activity was indicative of the level of excitability of the CNS (Masur et al. 1971, Barbas et al. 2006), and demonstrates the central inhibitory effect of CP in treated mice (Amos et al. 2001). Also, we recorded some signs of a depressionlike state in treated mice when subjected to forced swimming and tail suspension tests. These alterations could be due to chemical alterations in the brain amines of treated mice. These were not measured in this work, but they warrant further studies. The ataxia observed may be due to neuromuscular blockade (Perez et al. 1998) or to other unknown factors. The number of head-dips in the hole board test showed significant decrease in the exploratory behavior induced by $\mathrm{CP}$, indicating a decrease in the attraction of treated mice towards novelty (neophilia) (Brown and Nemes 2008).

We studied the effects of $\mathrm{CP}$ in two animal models of depression, FST, based on the original work reported (Porsolt et al. 1977) and TST (Yan et al. 2010). To evaluate the depression in most cases of treated models, stress-precipitated behaviors are assessed. Immobility is a state/posture that reflects the condition of hopelessness and despair (Holmes 2003). Depression and immobility are assumed to go in line with each other and it has been already shown that drugs with anti-depressant activity decrease immobility (Gersner et al. 2009). In our results, there was a significant increase in immobility time in CP-treated mice, possibly suggesting a depression-like state. The decreased motor activity and the general weakness induced by CP treatment may have been involved in the increased immobility in the FST and TST. Assessment of the possible neurochemical alterations associated with the reported actions will be studied further for better understanding of the depressivelike effect of $\mathrm{CP}$.

It has previously been shown that patients with cancer show some cognitive dysfunction following chemotherapy with agents such as CP (Pedersen et al. 2009). It would be of interest to study in detail some cognitive functions in mice with $\mathrm{CP}$-induced $\mathrm{CRF}$, and experimental agents that may mitigate these cognitive dysfunctions.

It was shown that oxidative stress and mitochondrial dysfunction were two major mechanisms involved in platinum induced neurotoxicity that triggered neuronal apoptosis (Cavaletti et al. 2011). The chemical changes in brain with respect to CRF models have previously been reported (Smogorzewski 2001). Additionally, formation of platinum-DNA-protein crosslinks and polymorphisms in DNA repair genes were also found to be associated with CP-induced neurotoxicity (Gulec et al. 2013). It was also shown that a reduced level of tGSH characterized $\mathrm{CP}$-induced cell death in brain and other tissues of treated animals (Altun et al. 2010). Activity of nitric oxide (NO), signal molecules of the CNS, also showed a significant decrease with CP (Azambuja et al. 2011). It is also known that CP causes marked organ damage that was characterized by elevated MDA level in tissues as a result of its direct peroxidative effect (Sener et al. 2012). CP nephrotoxicity raises the plasma concentration of the uremic toxin indoxyl sulphate (Ali and Al Moundhri 2006), and this uremic toxin has been shown to be involved in the central toxicity of CP (Iwata et al. 2007).

The present results indicated that administration of CP in mice prolonged the time taken in the hot plate and tail flick tests, and reduced the number of abdominal constrictions due to acetic acid injection. In a recent publication, reported in detail the polyneuropathy induced by administration of CP $(2.3 \mathrm{mg} / \mathrm{kg} /$ day $)$ every other day 6 times over two weeks for a total dose of $13.8 \mathrm{mg} / \mathrm{kg}$. It was found that thermal escape latencies were not affected by $\mathrm{CP}$, but hind paw tactile allodynia persisted for 46 days after treatment. These results are at variance with the present result, which seems to suggest a paradoxical finding of a CP-induced hypoalgesia when given at a single nephrotoxic dose of $20 \mathrm{mg} / \mathrm{kg}$. Cata et al. (2008) has previously shown that high doses of CP produced hypoalgesia whereas lower doses produce hyperalgesia. This result, based on chemical and thermal nociceptive tests (viz acetic acid-induced writhing test and hot plate and tail flick flick tests), needs to be verified and extended.

Various therapeutically efficient traditional and natural agents are subjected to studies to identify their effects on drug-induced neurotoxicity causing behavioral and motor alterations. In our previous study, we reported the effectiveness of curcumin against CP-induced behavioral changes (Al Moundhri et al. 2013). Green tea extract (polyphenols) has been proved to exhibit an antidepressant activity against chemical-induced autistic animals (Banji et al. 2011) and also showed a neuroprotective effect in oxaliplatin-induced neuropathy (Lee et al. 2012). In a recent study, it was showed that 
aqueous extract of Orbignya phalerata improved locomotion and motor activity in mice (Silva et al. 2012). We will test the possible effects of several natural products on the motor and behavioral changes seen after acute CP administration, and investigate further the possible mechanisms of these motor and behavioral changes in CP treated mice, including cognitive deficits.

\section{Conflict of Interest}

There is no conflict of interest.

\section{Acknowledgements}

Financial support for this work was from Sultan Qaboos University. S. Al-Abri is a medical student.

\section{References}

AKCAY A, TURKMEN K, LEE D, EDELSTEIN CL: Update on the diagnosis and management of acute kidney injury Int J Nephrol Renovasc Dis 3: 129-140, 2010.

AL-KHARUSI N, BABIKER HA, AL-SALAM S, WALY MI, NEMMAR A, AL-LAWATI I, YASIN J, BEEGAM S, ALI BH: Ellagic acid protects against cisplatin-induced nephrotoxicity in rats: a dose-dependent study. Eur Rev Med Pharmacol Sci 17: 299-310, 2013.

AL MOUNDHRI MS, AL-SALAM S, AL MAHROUQEE A, BEEGAM S, ALI BH: The effect of curcumin on oxaliplatin and Cisplatin neurotoxicity in rats: some behavioral, biochemical, and histopathological studies. J Med Toxicol 9: 25-33, 2013.

ALI BH, AL MOUNDHRI MS: Agents ameliorating or augmenting the nephrotoxicity of cisplatin and other platinum compounds: a review of some recent research. Food Chem Toxicol 44: 1173-1183, 2006.

ALI BH, BASHIR AK, BANNA NR, TANIRA MO: Central nervous system activity of Rhazya stricta (Decne) in mice. Clin Exp Pharmacol Physiol 22: 248-253, 1995.

ALI BH, BASHIR AK, TANIRA MO: The effect of Rhazya stricta Decne, a traditional medicinal plant, on spontaneous and drug-induced alterations in activity of rats. Pharmacol Biochem Behav 64: 455-460, 1999.

ALI BH, AL-MOUNDHRI M, TAGELDIN M, AL HUSSEINI IS, MANSOUR MA, NEMMAR A, TANIRA MO: Ontogenic aspects of cisplatin-induced nephrotoxicity in rats. Food Chem Toxicol 46: 3355-3359, 2008.

ALI BH, AL-SALAM S, AL HUSSENI I, KAYED RR, AL-MASROORI N, AL-HARTHI T, AL ZAABI M, NEMMAR A: Effects of Gum Arabic in rats with adenine-induced chronic renal failure. Exp Biol Med (Maywood) 235: 373-382, 2010.

ALI BH, ZIADA A, AL HUSSENI I, BEEGAM S, NEMMAR A: Motor and behavioral changes in rats with adenineinduced chronic renal failure: influence of acacia gum treatment. Exp Biol Med (Maywood) 236: 107-112, 2011.

ALTUN ZS, GUNES D, AKTAS S, ERBAYRAKTAR Z, OLGUN N: Protective effects of acetyl-L-carnitine on cisplatin cytotoxicity and oxidative stress in neuroblastoma. Neurochem Res 35: 437-443, 2010.

AMOS S, ADZU B, BINDA L, WAMBEBE C, GAMANIEL K: Neuropharmacological effect of the aqueous extract of Sphaeranthus senegalensis in mice. J Ethnopharmacol 78: 33-37, 2001.

ANDREOLI SP: Acute kidney injury in children. Pediatr Nephrol 24: 253-263, 2009.

AZAMBUJA AA, LUNARDELli A, NUNES FB, GASPARETO PB, DONADIO MV, DE FIGUEIREDO CE, DE OLIVEIRA JR: Effect of fructose-1,6-bisphosphate on the nephrotoxicity induced by cisplatin in rats. Inflammation 34: 67-71, 2011.

BALCOMBE JP: Laboratory environments and rodents' behavioural needs: a review. Lab Anim 40: 217-235, 2006.

BANJI D, BANJI OJ, ABBAGONI S, HAYATH MS, KAMBAM S, CHILUKA VL: Amelioration of behavioral aberrations and oxidative markers by green tea extract in valproate induced autism in animals. Brain Res 1410 : 141-151, 2011.

BARBAS D, ZAPPULLA JP, ANGERS S, BOUVIER M, MOHAMED HA, BYRNE JH, CASTELLUCCI VF, DESGROSEILLERS L: An aplysia dopamine1-like receptor: molecular and functional characterization. J Neurochem 96: 414-427, 2006. 
BERNOCCHI G, BOTTONE MG, PICCOLINI VM, DAL BO V, SANTIN G, De PASCALI SA, MigONI D, FANIZZI FP: Developing central nervous system and vulnerability to platinum compounds. Chemother Res Pract 2011: 315418, 2011.

BROWN GR, NEMES C: The exploratory behaviour of rats in the hole-board apparatus: is head-dipping a valid measure of neophilia? Behav Processes 78: 442-448, 2008.

CASTAGNE V, MOSER P, ROUX S, PORSOLT RD: Rodent models of depression: forced swim and tail suspension behavioral despair tests in rats and mice. Curr Protoc Neurosci Chapter 8: Unit 8.10A, 2011.

CATA JP, WENG HR, DOUGHERTY PM: Behavioral and electrophysiological studies in rats with cisplatin-induced chemoneuropathy. Brain Res 1230: 91-98, 2008.

CAVALETTI G, ALBERTI P, FRIGENI B, PIATTI M, SUSANI E: Chemotherapy-induced neuropathy. Curr Treat Options Neurol 13: 180-190, 2011.

CHIRINO YI, PEDRAZA-CHAVERRI J: Role of oxidative and nitrosative stress in cisplatin-induced nephrotoxicity. Exp Toxicol Pathol 61: 223-242, 2009.

COLLIER HO, DINNEEN LC, JOHNSON CA, SCHNEIDER C: The abdominal constriction response and its suppression by analgesic drugs in the mouse. Br J Pharmacol Chemother 32: 295-310, 1968.

DE JONGE MJ, VERWEIJ J: Renal toxicities of chemotherapy. Semin Oncol 33: 68-73, 2006.

DOS SANTOS NA, CARVALHO RODRIGUES MA, MARTINS NM, DOS SANTOS AC: Cisplatin-induced nephrotoxicity and targets of nephroprotection: an update. Arch Toxicol 86: 1233-1250, 2012.

EDDY NB, LEIMBACH D: Synthetic analgesics. II. Dithienylbutenyl- and dithienylbutylamines. J Pharmacol Exp Ther 107: 385-393, 1953.

FILE SE: Effects of chlorpromazine on exploration and habituation in the rat. Br J Pharmacol 49: 303-310, 1973.

FUJIMORI H: Potentiation of barbital hypnosis as an evaluation method for central nervous system depressants. Psychopharmacologia 7: 374-378, 1965.

GERSNER R, GORDON-KIWKOWITZ M, ZANGEN A: Automated behavioral analysis of limbs' activity in the forced swim test. $J$ Neurosci Methods 180: 82-86, 2009.

GULEC M, ORAL E, DURSUN OB, YUCEL A, HACIMUFTUOGLU A, AKCAY F, SULEYMAN H: Mirtazapine protects against cisplatin-induced oxidative stress and DNA damage in the rat brain. Psychiatry Clin Neurosci 67: 50-58, 2013.

HEDAYATI SS, YALAMANCHILI V, FINKELSTEIN FO: A practical approach to the treatment of depression in patients with chronic kidney disease and end-stage renal disease. Kidney Int 81: 247-255, 2012.

HOLMES PV: Rodent models of depression: reexamining validity without anthropomorphic inference. Crit Rev Neurobiol 15: 143-174, 2003.

IWATA K, WATANABE H, MORISAKI T, MATSUZAKI T, OHMURA T, HAMADA A, SAITO H: Involvement of indoxyl sulfate in renal and central nervous system toxicities during cisplatin-induced acute renal failure. Pharm Res 24: 662-671, 2007.

KANG KP, KIM DH, JUNG YJ, LEE AS, LEE S, LEE SY, JANG KY, SUNG MJ, PARK SK, KIM W: Alpha-lipoic acid attenuates cisplatin-induced acute kidney injury in mice by suppressing renal inflammation. Nephrol Dial Transplant 24: 3012-3020, 2009.

KONG D, ZHUO L, GAO C, SHI S, WANG N, HUANG Z, LI W, HAO L: Erythropoietin protects against cisplatininduced nephrotoxicity by attenuating endoplasmic reticulum stress-induced apoptosis. J Nephrol 26: 219-227, 2013.

LEE JS, KIM YT, JEON EK, WON HS, CHO YS, KO YH: Effect of green tea extracts on oxaliplatin-induced peripheral neuropathy in rats. BMC Complement Altern Med 12: 124, 2012.

LEU L, BARIBEAULT D: A comparison of the rates of cisplatin (cDDP)--induced nephrotoxicity associated with sodium loading or sodium loading with forced diuresis as a preventative measure. J Oncol Pharm Pract 16: 167-171, 2010.

LI PK, BURDMANN EA, MEHTA RL: Acute kidney injury: global health alert. Transplantation 95: 653-657, 2013.

LI XB, SCHLUESENER HJ: Therapeutic effects of cisplatin on rat experimental autoimmune encephalomyelitis. Arch Immunol Ther Exp (Warsz) 54: 51-53, 2006. 
MASUR J, MARTZ RM, CARLINI EA: Effects of acute and chronic administration of Cannabis sativa and (-) delta9trans-tetrahydrocannabinol on the behavior of rats in an open-field arena. Psychopharmacologia 19: 388-397, 1971.

MITAZAKI S, HASHIMOTO M, MATSUHASHI Y, HONMA S, SUTO M, KATO N, NAKAGAWASAI O, TAN-NO K, HIRAIWA K, YOSHIDA M, ABE S: Interleukin-6 modulates oxidative stress produced during the development of cisplatin nephrotoxicity. Life Sci 92: 694-700, 2013.

PABLA N, DONG Z: Curtailing side effects in chemotherapy: a tale of PKCdelta in cisplatin treatment. Oncotarget 3: 107-111, 2012.

PABLA N, MURPHY RF, LIU K, DONG Z: The copper transporter Ctr1 contributes to cisplatin uptake by renal tubular cells during cisplatin nephrotoxicity. Am J Physiol 296: F505-F511, 2009.

PARK HJ, STOKES JA, PIRIE E, SKAHEN J, SHTAERMAN Y, YAKSH TL: Persistent hyperalgesia in the cisplatintreated mouse as defined by threshold measures, the conditioned place preference paradigm, and changes in dorsal root ganglia activated transcription factor 3: the effects of gabapentin, ketorolac, and etanercept. Anesth Analg 116: 224-231, 2013.

PEDERSEN AD, ROSSEN P, MEHLSEN MY, PEDERSEN CG, ZACHARIAE R, VON DER MAASE H: Long-term cognitive function following chemotherapy in patients with testicular cancer. J Int Neuropsychol Soc 15: 296301, 2009.

PEREZ RM, PEREZ JA, GARCIA LM, SOSSA H: Neuropharmacological activity of Solanum nigrum fruit. J Ethnopharmacol 62: 43-48, 1998.

PORSOLT RD, BERTIN A, JALFRE M: Behavioral despair in mice: a primary screening test for antidepressants. Arch Int Pharmacodyn Ther 229: 327-336, 1977.

SAAD SY, NAJJAR TA, AL-SOHAIBANI MO: The effect of rebamipide on cisplatin-induced nephrotoxicity in rats. Pharmacol Res 42: 81-86, 2000.

SANCHEZ-GONZALEZ PD, LOPEZ-HERNANDEZ FJ, LOPEZ-NOVOA JM, MORALES AI: An integrative view of the pathophysiological events leading to cisplatin nephrotoxicity. Crit Rev Toxicol 41: 803-821, 2011.

SENER MT, SENER E, TOK A, POLAT B, CINAR I, POLAT H, AKCAY F, SULEYMAN H: Biochemical and histologic study of lethal cisplatin nephrotoxicity prevention by mirtazapine. Pharmacol Rep 64: 594-602, 2012.

SILVA AP, CERQUEIRA GS, NUNES LC, DE FREITAS RM: Effects of an aqueous extract of Orbignya phalerata Mart on locomotor activity and motor coordination in mice and as antioxidant in vitro. Pharmazie 67: 260-263, 2012.

SMOGORZEWSKI MJ: Central nervous dysfunction in uremia. Am J Kidney Dis 38: S122-S128, 2001.

STERU L, CHERMAT R, THIERRY B, SIMON P: The tail suspension test: a new method for screening antidepressants in mice. Psychopharmacology (Berl) 85: 367-370, 1985.

VERA G, CHIARLONE A, MARTIN MI, ABALO R: Altered feeding behaviour induced by long-term cisplatin in rats. Auton Neurosci 126-127: 81-92, 2006.

VERVLIET B, RAES F: Criteria of validity in experimental psychopathology: application to models of anxiety and depression. Psychol Med 43: 2241-2244, 2013.

WASEEM M, PARVEZ S: Mitochondrial dysfunction mediated cisplatin induced toxicity: modulatory role of curcumin. Food Chem Toxicol 53: 334-342, 2013.

WILD KD, MCCORMICK J, BILSKY EJ, VANDERAH T, MCNUTT RW, CHANG KJ, PORRECA F: Antinociceptive actions of BW373U86 in the mouse. J Pharmacol Exp Ther 267: 858-865, 1993.

YAN HC, CAO X, DAS M, ZHU XH, GAO TM: Behavioral animal models of depression. Neurosci Bull 26: 327-337, 2010.

ZALAI D, SZEIFERT L, NOVAK M: Psychological distress and depression in patients with chronic kidney disease. Semin Dial 25: 428-438, 2012. 